\title{
ADDITIONAL ELECTROCARDIOGRAPHIC SIGNS OF CARDIAC PAIN
}

\author{
BY \\ WILLIAM EVANS AND R. K. PILLAY \\ From the Cardiac Department of the London Hospital \\ Received July 6, 1956
}

The recognition of the lesser changes in the electrocardiogram that indicate a limited injury of the myocardium from coronary arterial disease has reduced significantly the number of patients with cardiac pain erstwhile regarded as showing a normal tracing. Such changes include depression of any part of the S-T segment, low or blunt $T$ waves, terminal dipping of the $T$ wave, inversion of the $U$ wave, notching of the descending limb of the QRS in lead CR7, and the appearance of a $Q$ wave in IIIR when it has been absent in lead III (Evans and McRae, 1952; Evans, 1951). Although such deformities in the cardiogram are small ones, they loom large in their significance, because in the first place they confirm a cardiac source for pain in the chest, and secondly because the mortality rate among patients showing them is the same as in those with gross changes like deeply inverted $\mathrm{T}$ waves with or without abnormal $\mathrm{Q}$ waves.

The purpose of this inquiry has been to find other cardiographic changes which might signify that chest pain in a given patient arises from coronary arterial disease. We have sought the meaning of two other lesser deformities; the first has been a depression of the T-U segment, and the second the presence of a natural $Q$ wave in certain leads.

\section{OUTLINE OF THE INVESTIGATION}

Before either of the two cardiographic changes could be accepted as representing a myocardial fault, it was required of them to satisfy certain probationary tests. First, the deformity should be absent from the electrocardiogram of healthy youths, although it might occasionally appear in the tracings recorded in uncomplaining elderly subjects when it could indicate a painless cardiac injury. Secondly, the deformity was expected in tracings from patients with chest pain that seemed characteristic of cardiac pain, either as a lone sign or in company with other signs accepted as evidence of coronary arterial disease. Thirdly, the empirical deformity residing in a tracing recorded at rest should be frequently joined in the exercise electrocardiogram by more obvious changes accepted as meaning a positive test. Fourthly, the cardiographic deformity might in time give way to unequivocal changes of cardiac infarction, or the patient exhibiting the sign might die from extension of the infarct.

The electrocardiogram in each instance consisted of the four bipolar limb leads I, II, III and IIIR (lead III recorded during deep inspiration), together with the three bipolar chest leads CR1, CR4 and CR7. The bipolar leads were deliberately chosen as being more proficient than unipolar leads in the investigation of cardiac pain.

We first examined the tracing in two separate series each comprising 500 healthy adults over the age of 20 years, who showed neither clinical nor radiological signs of cardiovascular disease. It was next examined in 200 consecutive patients in whom the chest pain resembled cardiac pain, but the tracing had been reported as normal on casual inspection, and in another 500 patients with cardiac pain confirmed by characteristic electrocardiographic changes. Lastly, the cardiogram was examined in 250 patients with painless heart disease. It was in these 1950 cases that we sought 
the two newer electrocardiographic changes that we submitted to special scrutiny in order to test their dependability as evidence of a limited myocardial injury. The results of the inquiry in regard to each cardiographic deformity are now to be discussed separately.

\section{DEPRESSION OF THE T-U SEGMENT}

The significance of a sharp dip of the descending limb of the $T$ wave beyond the iso-electric level has already received emphasis (Evans and McRae, 1952; Evans, 1955), for it proved to be as useful as frank inversion of the $T$ wave in the recognition of a myocardial injury from coronary arterial disease.

On this occasion the significance of a less abrupt and more gradual depression in the $\mathrm{T}-\mathrm{U}$ segment has been examined. This trough-like deformity involved the entire length of the $T-U$ period, and although shallow, it extended below the iso-electric line, here determined by reference to the U-P interval. In the presence of tachycardia, therefore, it is not possible to recognize this deformity in that the early incidence of the $P$ wave in this circumstance does not allow the curve to return to its iso-electric phase for the U-P interval is eliminated (Fig. 1).

In our cases the downward projection of the T-U depression beyond the U-P line was never greater than $1.0 \mathrm{~mm}$., and in order to be discernible, and consequently significant, it had to be $0.25 \mathrm{~mm}$. (Fig. 2).

When this deformity was sought in 500 consecutive electrocardiograms recorded from healthy adults it was never found. Later, it was looked

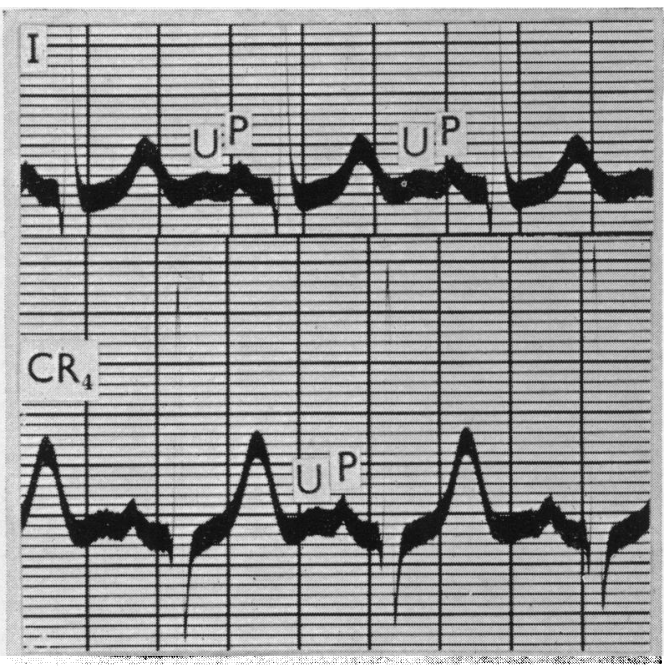

Fig. 1.-Apparent depression of the T-U segment. Tachycardia has annulled the U-P interval so that the $P$ wave is superimposed on the final phase of the $U$ wave. for in tracings from 250 patients with diverse

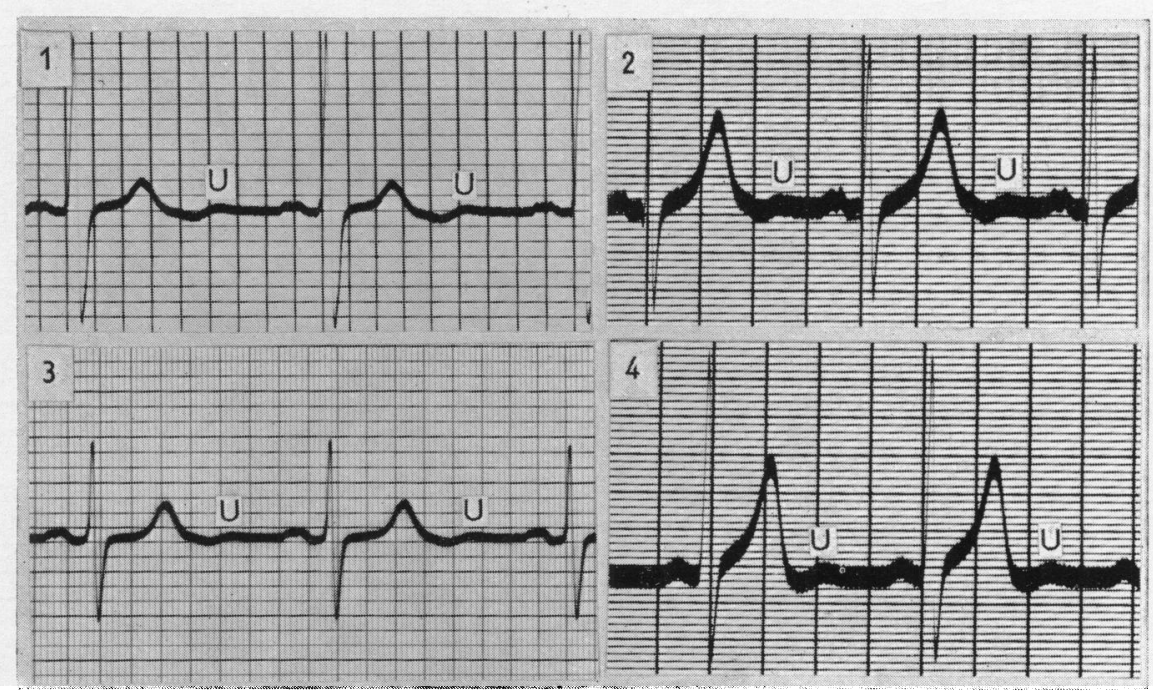

FIG. 2.-Depression of the T-U segment in lead CR4 in four patients with cardiac pain. The horizontal lines indicating voltage, mark out intervals of $2 \mathrm{~mm}$. in Cases 1 and 3 and $1 \mathrm{~mm}$. in Cases 2 and 4 . 
forms of painless heart disease where coronary arterial disease was not suspected; it was met with once in a child with the Fallot syndrome.

Depression of the T-U segment was next sought in 500 patients, considered to have cardiac pain, but in whom gross electrocardiographic changes were absent; it was found 15 times.

The sign was best seen in lead CR4 in 12 of the cases, and in CR7 in the other 3; in eight it appeared in lead I as well. In eight it was associated with other lesser electrocardiographic signs, namely depression of the S-T segment in IIIR in five, notching of the RS limb in CR7 in two, addition of $\mathrm{a} Q$ in IIIR in one, and inversion of the $U$ wave in another. In seven patients depression of the T-U segment was there by itself as the only discernible deformity in an otherwise normal tracing. The exercise electrocardiogram, recorded in five, gave a positive test in four (Fig. 3). Two of the patients have since died suddenly from extension of cardiac infarction, which was confirmed at necropsy in both instances when the infarct was found at the back of the left ventricle.

\section{Natural Q Waves in Limb and Chest Leads}

By definition any downward deflection preceding the $R$ wave is a $Q$ wave. In adults a $Q$ has usually been regarded as natural if its width does not exceed 0.04 second, and if its depth does not

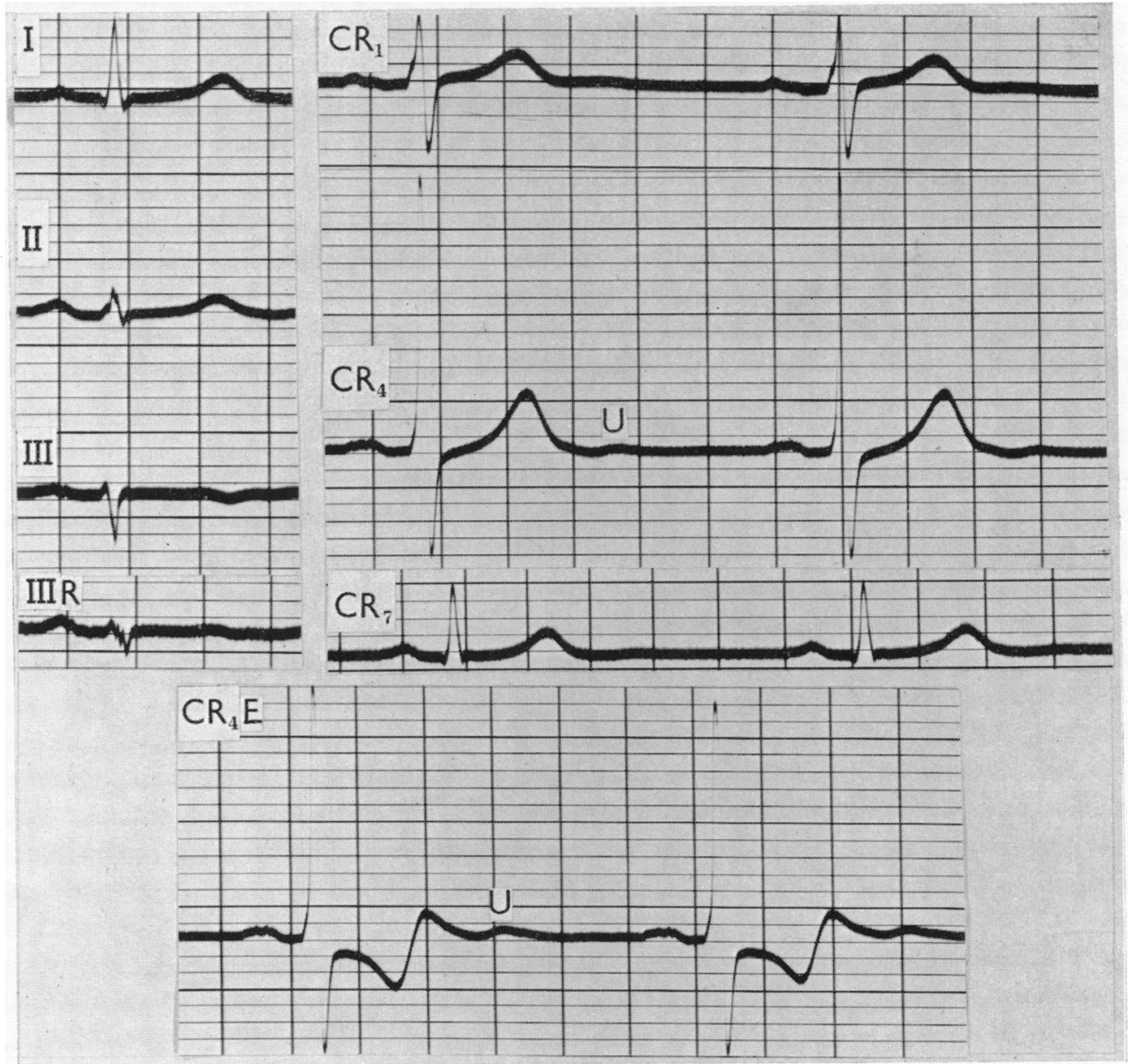

FIG. 3.-Depression of the T-U segment in CR4 was the only cardiographic abnormality in a patient with cardiac pain. The exercise tracing (CR4E) was a positive test where the $T-U$ interval is natural. 
exceed $4 \mathrm{~mm}$. in the limb leads I, II, and IIIR; it may be deeper in lead III, especially in children.

Speaking on the initial ventricular deflection in the electrocardiogram of the young healthy subject, Kossman et al. (1936) said that the maximal measurement of Q in each of leads I, II, and III in 178 cases was $2 \mathrm{~mm} ., 2.5 \mathrm{~mm}$. and $3.0 \mathrm{~mm}$. respectively. Wilson (1937) found that the depth of the $Q$ wave in leads I, II and III, was less than $2.5 \mathrm{~mm} ., 3.3 \mathrm{~mm}$. and $3.5 \mathrm{~mm}$. respectively in 104 healthy subjects between the ages of 20 and 30 years. Lepeschkin (1951), seeking the same measurement in 4000 healthy adults collected from various sources, found the corresponding values to be $3 \mathrm{~mm}$., $4 \mathrm{~mm}$., and $4.5 \mathrm{~mm}$. Graybiel (1951) mentioned that a $Q$ of less than $3 \mathrm{~mm}$. in depth may be seen in lead I in half the tracings from healthy subjects, and in leads II and III in two-thirds of them.

Several workers have given their views on the maximum depth of the $\mathrm{Q}$ wave in chest leads. Deeds and Barnes (1940) found this to be $1.7 \mathrm{~mm}$. deep in CR5 and $2.6 \mathrm{~mm}$. in CR6 in 100 healthy adults; a Q was only once present in CR1. Levine (1948) mentioned that a Q wave was not normally seen in the chest leads V1 to V3, and was not prominent until V5 or V6 was reached; such a $Q$ was thin, rarely longer than 0.02 second, and was never more than a small fraction of the $R$ wave. Lepeschkin (1951) in a series of healthy subjects over the age of 20, reported that the maximal depth of the $Q$ was $0.5 \mathrm{~mm}$. in V3, $1.6 \mathrm{~mm}$. in V4, $3.0 \mathrm{~mm}$. in V5 and $2.7 \mathrm{~mm}$. in V6; it was absent from leads V1 and V2. Graybiel (1951) also mentioned that in healthy subjects a $Q$ was never seen in chest leads V1 and V2; it was rare to see a small Q in V3, but it was seen sometimes in V4, commonly in V5, and frequently in V6. White (1951) similarly stated that $Q$ waves might be absent from chest leads in health, but that small ones appeared in leads over the left ventricle.

It will be seen, therefore, that these several observers are agreed that natural $Q$ waves are expected in leads taken over the left chest, but are not found in health in leads recorded over the right ventricle. Our findings are in accord with these views, but we have been unable to find any observations made on the normality or otherwise of natural $Q$ waves appearing in a combination of limb and chest leads, and it is with this problem that we are concerned.

Lead Distribution of Natural $Q$ Waves. In addition to a search for natural $Q$ waves in each of the seven leads used in this investigation, we also sought them in 33 different lead combinations. When this was done in 500 symptomless and apparently healthy adults, a $Q$ was absent in 19 and present in 14 combinations. The significance of this finding is now to be examined for each group.

Absence of natural $Q$ waves in the healthy series. The particular leads that did not show a $Q$ wave in the healthy series are listed in Table I. Thus, a $\mathrm{Q}$ was absent in four individual leads, in four two-lead combinations, in four three-lead combinations, in five four-lead combinations, and in two five-lead combinations.

The absence of $Q$ waves in these lead arrangements might mean that the distribution of electrical

TABLE I

Single Leads or Combination of Leads that did NOT SHOW a Q WAVE IN 500 Symptomless AND Apparently Healthy Subjects

\begin{tabular}{|c|c|c|}
\hline \multicolumn{2}{|c|}{$\begin{array}{l}\text { Number of leads } \\
\text { in combination }\end{array}$} & Leads specified \\
\hline $\begin{array}{l}\text { Single lead } \\
\text { Two leads } \\
\text { Three leads } \\
\text { Four leads } \\
\text { Five leads }\end{array}$ & $\begin{array}{l}\cdots \\
\cdots \\
\cdots \\
\cdots\end{array}$ & $\begin{array}{l}\text { II. IIIR. CR4. } \\
\text { I and II. I and CR4. II and CR4. CR4 and CR7. } \\
\text { I, III, and IIIR. I, II, and CR4. II, CR4, and CR7. III, IIIR, } \\
\text { and CR4. } \\
\text { I, II, III, and IIIR. I, III, IIIR, and CR4. I, III, IIIR, and CR7. } \\
\text { II, III, IIIR, and CR4. III, IIIR, CR4, and CR7. } \\
\text { I, II, III, IIIR, and CR4. I, III, IIIR, CR4, and CR7. }\end{array}$ \\
\hline
\end{tabular}


potential associated with heart contraction is such as not to allow them to appear, and that their presence would suggest that the spread of the electrical forces was being modified by a myocardial injury. It was necessary, therefore, to look for $Q$ waves in the same lead arrangement recorded in patients with chest pain that seemed characteristic of cardiac pain.

A natural Q, which was never an isolated finding in lead I among the 500 healthy subjects, was met with once in the series of patients with chest pain (Fig. 4).

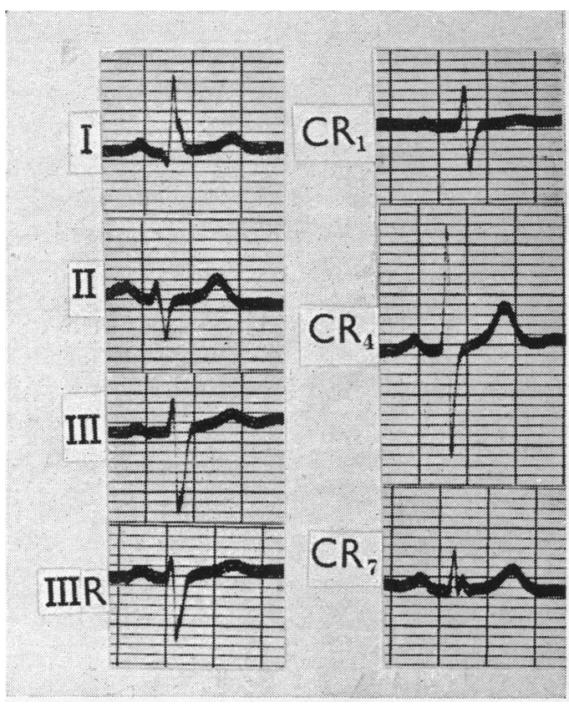

Fig. 4.-A $Q$ wave in lead I was the only deformity in the electrocardiogram of a patient with cardiac-like pain. The notch in RS7 is not considered abnormal in that it is placed low on the stem and a $\mathrm{qR}$ pattern is absent.

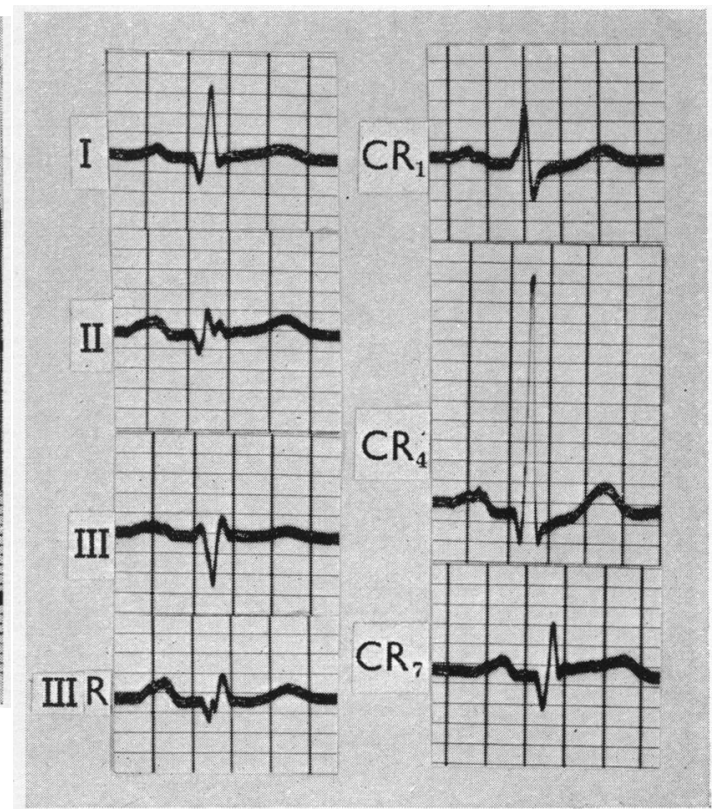

FIG. 5.-A Q wave, absent in III, makes its appearance in IIIR. The tracing was from a patient with proved cardiac pain.

This investigation confirmed the view that the appearance of a $Q$ wave in IIIR that had been absent in III was evidence of cardiac infarction in a patient with chest pain. This occurred three times as a lone cardiographic abnormality in our series (Fig. 5), and since its implication has been discussed fully elsewhere (Evans, 1951), it will not be described further in this paper.

In the two other single leads, namely II and CR4, no patient with chest pain in the series showed a $\mathrm{Q}$ wave in these leads, nor did any in the group of healthy subjects.

We have been reluctant to pronounce on the significance of a $Q$ wave in the other lead combinations named in Table I, because although they never showed a $Q$ in the series of healthy subjects, neither did they in patients with cardiac pain whose electrocardiograms subsequently gave unequivocal evidence of cardiac infarction.

Presence of natural $Q$ waves in the healthy series. It might be held, and with justification, that a $Q$ that appeared frequently in certain lead combinations among uncomplaining and apparently healthy subjects could not be regarded as evidence of a myocardial injury should it appear in patients with chest pain. In the case of the lead arrangement I-CR4-CR7, however, we were impressed by the relative absence of a $\mathrm{Q}$ wave in the younger group and its frequency in the older group. Thus, among 42 cases exhibiting this cardiographic sign, there were only 6 under 50 , while 22 were over 60 years of age (see Table II). In order to test the meaning of this finding and to discover whether this told of the effects of coronary arterial disease, the 42 supposedly healthy subjects presenting this sign were recalled for examination. Twenty failed to attend and in most of these it was ascertained that they felt it was unnecessary to present themselves for further examination in that 
they relied on the reassurance given them at the first. One case, however, had died at home from pneumonia.

Among the 22 who responded we considered that one was too old and frail to be subjected to an exercise electrocardiogram. Such a test was carried out in 15 when nine gave a positive result, four a doubtful positive, while in two it was regarded as negative. At this stage the significance of such a result came under review, especially as to the meaning of a negative response because in our two cases a $Q$ in the combination I-CR4-CR7 was associated with other abnormal signs (Fig. 6). While we have regarded the positive test as likely to be significant we would hesitate to accept a negative one as opposing a doubtful change in the resting cardiogram as meaning a myocardial fault, unless this applied to a number of the cases.

In the remaining 6 of the 22 cases that attended for re-examination a $Q$ wave was no longer present in the I-CR4-CR7 combination, and this led us to consider a definition of a significant natural $Q$ wave, for inspection of the first electrocardiogram taken in these six cases showed that it was a diminutive wave, appearing as a mere point, and less than $1 \mathrm{~mm}$. in depth (Fig. 7). We would, therefore, define a significant natural $Q$ in adults as being over $1 \mathrm{~mm}$., but

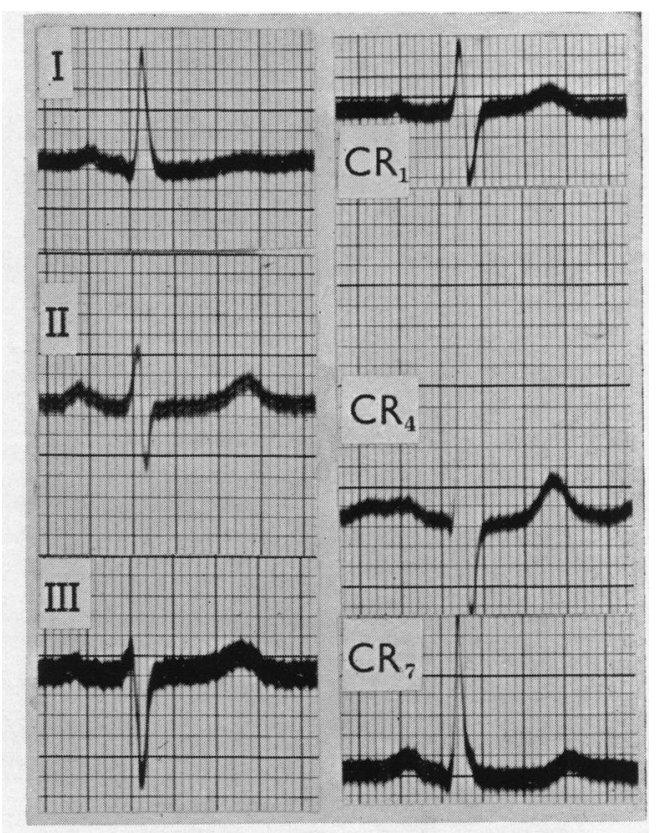

FIG. 6.-A natural $Q$ wave in leads I, CR4, and CR7 from a patient with cardiac pain is accompanied by S-T depression in I and CR7. An exercise test failed to exaggerate this deformity. not exceeding $3 \mathrm{~mm}$. in depth, except in lead III, and not exceeding 0.04 second in width.

We next sought a $Q$ wave in the lead combination I-CR4-CR7 in the series of patients with chest pain that seemed to be characteristic of cardiac pain. There were six such cases. When their progress was followed it was found that more obvious electrocardiographic changes had taken place in association with recurrent attacks of chest pain in four (Fig 8 and 9). One other had died from extension of cardiac infarction (Fig. 10). The remaining patient continues

TABLE II

Age Incidence and Lead Distribution of Natural Q Waves among 500 Healthy Adults

\begin{tabular}{|c|c|c|c|c|c|c|c|c|c|}
\hline \multicolumn{4}{|c|}{$\begin{array}{l}\text { Age groups } \\
\text { in decades }\end{array}$} & $\begin{array}{c}20 \text { to } 29 \\
\text { years }\end{array}$ & $\begin{array}{c}30 \text { to } 39 \\
\text { years }\end{array}$ & $\begin{array}{c}40 \text { to } 49 \\
\text { years }\end{array}$ & $\begin{array}{c}50 \text { to } 59 \\
\text { years }\end{array}$ & $\begin{array}{c}60 \text { to } 69 \\
\text { years }\end{array}$ & $\begin{array}{l}70 \text { years } \\
\text { or over }\end{array}$ \\
\hline \multicolumn{4}{|c|}{ Number of cases } & 50 & 86 & 129 & 143 & 79 & 13 \\
\hline 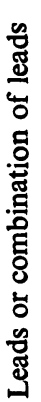 & $\begin{array}{l}\text { Absent in all leads (48) } \\
\text { CR7 (38) } \\
\text { I and CR7 (99) } \\
\text { I, CR4, and CR7 (42) } \\
\text { I, II, and CR7 (48) } \\
\text { I, II, CR4, and CR7 (44) } \\
\text { I, II, III, IIIR, CR4, and CR } \\
\text { I, II, III, IIIR, and CR7 (37) } \\
\text { II and CR7 (13) } \\
\text { II, III, and IIIR (5) } \ldots \\
\text { II, III, IIIR, and CR7 (71) } \\
\text { II, III, IIIR, CR4, and CR7 } \\
\text { III and IIIR (5) } \\
\text { III, IIIR, and CR7 (4) }\end{array}$ & $\begin{array}{l}\ldots \\
\ldots \\
\ldots \\
\ldots \\
\cdots \\
\ddot{7}(35) \\
\ldots \\
\ldots \\
\ddot{(11)} \\
\ldots \\
\ldots\end{array}$ & 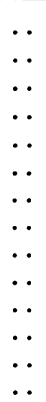 & $\begin{array}{r}8 \\
2 \\
4 \\
0 \\
4 \\
5 \\
4 \\
5 \\
0 \\
0 \\
13 \\
1 \\
2 \\
2\end{array}$ & $\begin{array}{r}5 \\
6 \\
20 \\
2 \\
10 \\
3 \\
6 \\
6 \\
3 \\
1 \\
22 \\
0 \\
2 \\
0\end{array}$ & $\begin{array}{r}10 \\
14 \\
28 \\
4 \\
13 \\
13 \\
7 \\
10 \\
5 \\
1 \\
15 \\
7 \\
0 \\
2\end{array}$ & $\begin{array}{r}15 \\
13 \\
34 \\
14 \\
13 \\
11 \\
10 \\
14 \\
2 \\
2 \\
12 \\
2 \\
1 \\
0\end{array}$ & $\begin{array}{r}9 \\
3 \\
13 \\
16 \\
7 \\
10 \\
8 \\
2 \\
3 \\
1 \\
6 \\
1 \\
0 \\
0\end{array}$ & $\begin{array}{l}1 \\
0 \\
0 \\
6 \\
1 \\
2 \\
0 \\
0 \\
0 \\
0 \\
3 \\
0 \\
0 \\
0\end{array}$ \\
\hline
\end{tabular}

Numerals in and outside the brackets denote number of cases. 


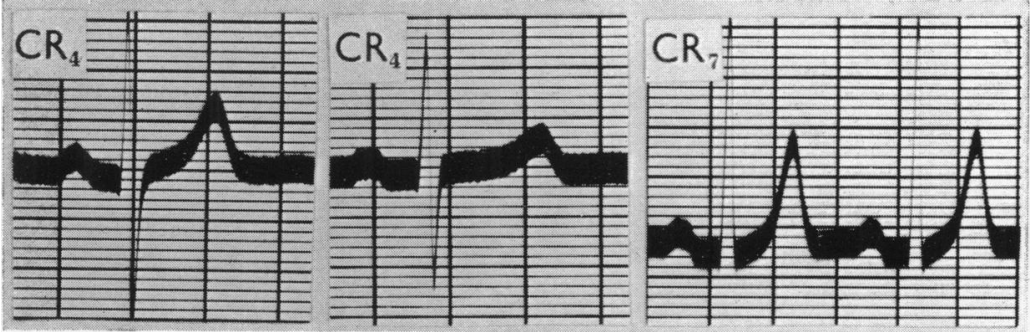

Fig. 7.-A diminutive, and therefore insignificant, $Q$ wave in tracings taken from three healthy subjects. The $Q$ is seen as a mere point.

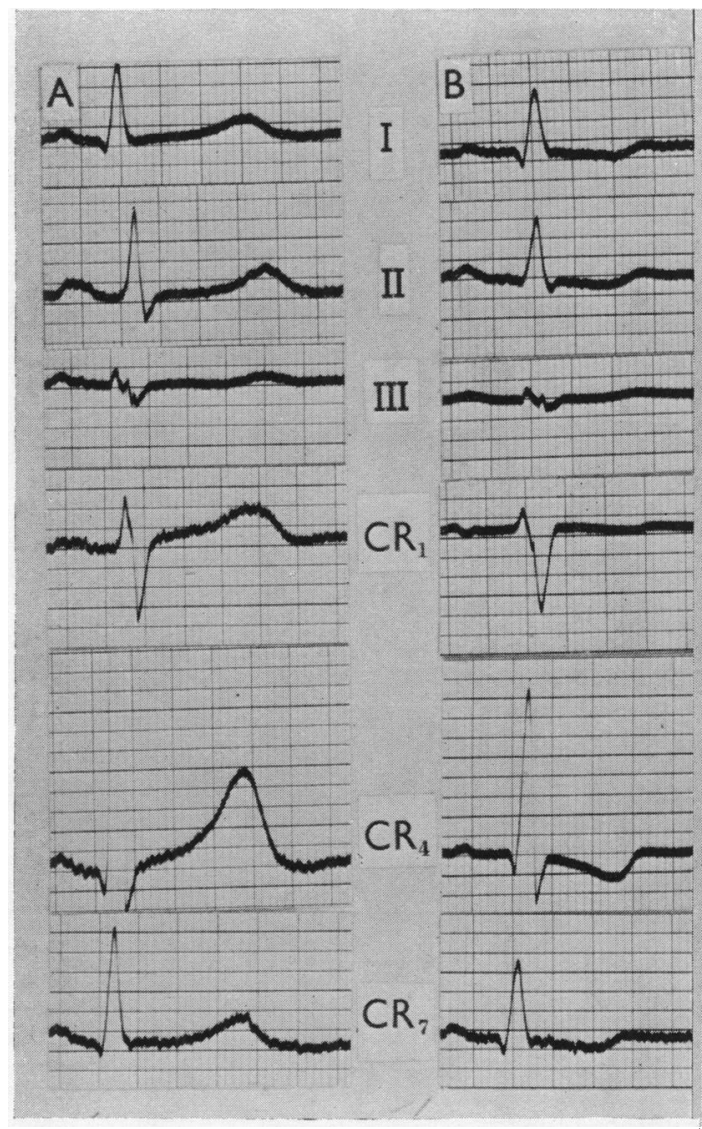

FIG. 8.-A natural $Q$ in leads I, CR4, and CR7 was the only abnormal sign in the cardiogram (A) taken from a patient with cardiac pain. Another time the tracing (B) showed more obvious changes from extension of the cardiac infarct.

Fig. 9.-A natural $Q$ in leads I, CR4, and CR7 was the only abnormal sign in the cardiogram (A) from a patient with cardiac pain. More obvious changes of cardiac infarction are seen in (B) recorded two weeks later.

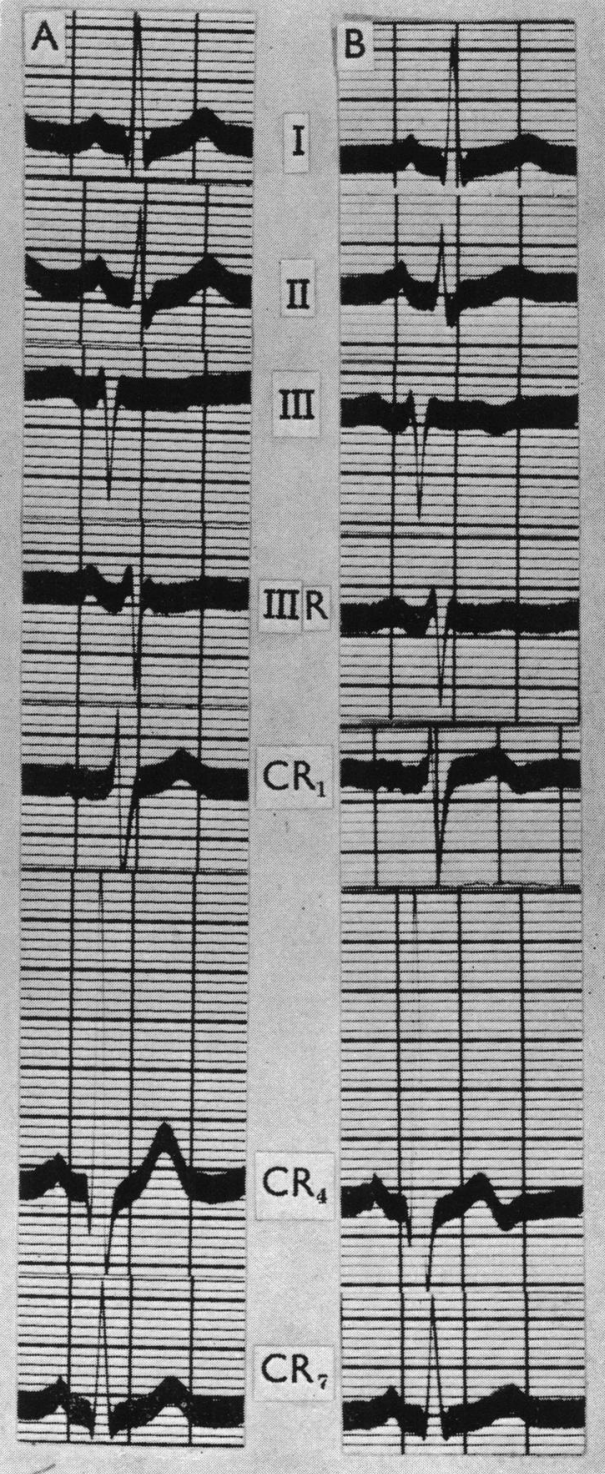


to experience typical attacks of cardiac pain although his cardiogram remains unchanged. These findings are at variance with the suggestions made by Burch (1956) that patients showing an absence of $Q$ in leads $I$, V5 and V6 are prone to cardiac pain and septal fibrosis in the absence of coronary occlusion. Indeed, apart from finding a $Q$ in the lead combination I-CR4-CR7 in six patients with cardiac pain, we found it absent in 58 of the 500 healthy subjects.

In that a $\mathrm{Q}$ in this lead combination may prove to be significant, the combination I-CR4 could prove to be equally so should a displacement of the heart cause the CR7 lead to occupy a position in relation to the heart farther to the right than its customary one opposite the postero-lateral border of the left ventricle. No such example was, however, met with in the course of this investigation.

\section{Summary AND CONCLUSIONS}

The competence of two further lesser electrocardiographic signs in the diagnosis of a limited myocardial injury from coronary arterial disease has been examined.

The two probationary signs were a depression of the T-U segment, and the presence in certain lead

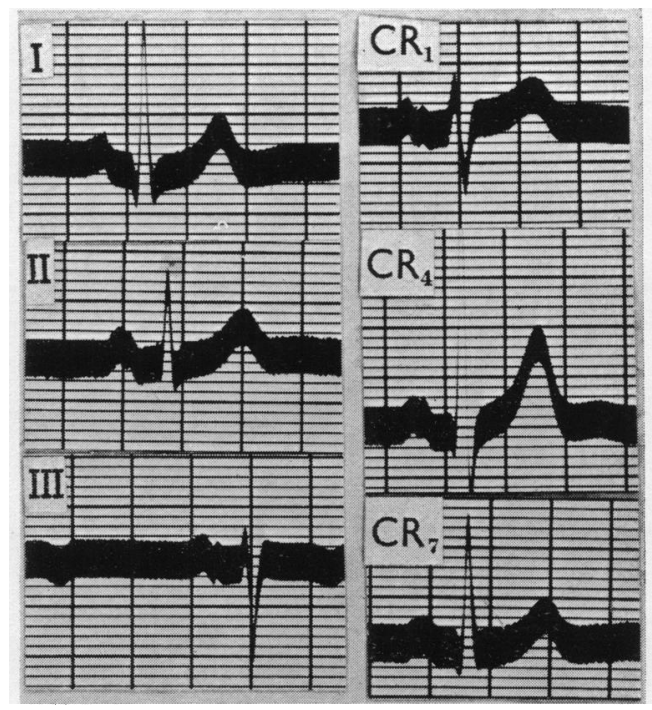

FIG. 10.-A natural $Q$ wave in leads I, CR4, and CR7 was the only abnormal sign in a patient with cardiac pain who died three months later from further cardiac infarction. combinations of a natural $\mathrm{Q}$ wave, defined as one not less than $1 \mathrm{~mm}$. and not more than $3 \mathrm{~mm}$. in depth, and no wider than 0.04 second.

To prove the validity of each cardiographic sign as a teller of cardiac pain we required that it should be absent in healthy youths and infrequent in uncomplaining elderly subjects; when present in such symptomless subject or in patients with chest pain, the sign was expected either to give way later to more obvious ones indicating cardiac infarction, or to be joined with changes in the exercise electrocardiogram that meant a positive test. The demise of a patient from cardiac infarction without offering intermediate electrocardiographic evidence was also accepted as corroboration of the reliability of the probationary sign.

Depression of the T-U segment below the isoelectric line of the U-P period proved to be an undisputed sign of a myocardial injury from coronary arterial disease. It is not possible to discover this change in the presence of tachycardia because the early incidence of the $P$ wave prevents the return of the curve to an iso-electric phase during the U-P period.

The incidence of natural $Q$ waves in cardiograms from healthy subjects and from patients with cardiac pain led us to draw the following conclusions. First, a natural $\mathrm{Q}$ in the single leads or in lead combinations, listed in Table $I$ is evidence of a myocardial injury. Secondly, although a $Q$ in the lead combination I-CR4-CR7 was seen in healthy subjects, since it usually appeared in the older age group, and since it was found as the only unnatural sign in the cardiogram recorded from patients in whom chest pain was later confirmed to be cardiac pain when extension of the cardiac infarct had taken place, we believe that $Q$ in this lead combination may also prove to be an early electrocardiographic sign of a myocardial injury.

We wish to acknowledge the help we obtained from Dr. J. W. Fawcett earlier in the investigation.

\section{REFERENCES}

Burch, G. E. (1956). Amer. Heart J., 51, 487.

Deeds, D., and Barnes, A. R. (1940). Amer. Heart J., 20, 261.

Evans, W. (1951). Brit. Heart J., 13, 457. 
Evans, W. (1955). Brit. Heart J., 17, 15. and McRae, C. (1952). Brit. Heart J., 14, 429.

Graybiel, A. (1951). Disorders of the Heart and Circulation. Nelson and Sons, New York. Kossman, C. E., Shearer, M., and Texon, M. (1936). Amer. Heart J., 2, 346.

Lepeschkin, E. (1951). Modern Electrocardiography. Baillière, Tindall \& Co. (Lond.). Levine, S. A. (1948). Clinical Heart Disease. Saunders, Phil.

White, P. D. (1951). Heart Disease. 4th ed. Macmillan, New York.

Wilson, F. N. (1937). Trans. Assoc. Life Ins. Med. Dir., 24, 96. 